\title{
Reallocation in modal aerosol models: impacts on predicting aerosol radiative effects
}

\author{
T. Korhola ${ }^{1}$, H. Kokkola ${ }^{2}$, H. Korhonen ${ }^{2}$, A.-I. Partanen ${ }^{2}$, A. Laaksonen ${ }^{2,3}$, K. E. J. Lehtinen ${ }^{1,2}$, and \\ S. Romakkaniemi ${ }^{1}$ \\ ${ }^{1}$ Department of Applied Physics, University of Eastern Finland, P.O. Box 1627, 70211 Kuopio, Finland \\ ${ }^{2}$ Finnish Meteorological Institute, P.O. Box 1627, 70211 Kuopio, Finland \\ ${ }^{3}$ Finnish Meteorological Institute, P.O. Box 503, 00101 Helsinki, Finland
}

Correspondence to: T. Korhola (tapani.korhola@uef.fi)

Received: 14 June 2013 - Published in Geosci. Model Dev. Discuss.: 6 August 2013

Revised: 28 November 2013 - Accepted: 12 December 2013 - Published: 28 January 2014

\begin{abstract}
Atmospheric models often represent the aerosol particle size distribution with a modal approach, in which particles are described with log-normal modes within predetermined size ranges. This approach reallocates particles numerically from one mode to another for example during particle growth, potentially leading to artificial changes in the aerosol size distribution. In this study we analysed how the modal reallocation affects climate-relevant variables: cloud droplet number concentration (CDNC), aerosol-cloud interaction parameter (ACI) and light extinction coefficient $\left(q_{\text {ext }}\right)$. The ACI parameter gives the response of CDNC to a change in total aerosol number concentration. We compared these variables between a modal model (with and without reallocation routines) and a high resolution sectional model, which was considered a reference model. We analysed the relative differences in the chosen variables in four experiments designed to assess the influence of atmospheric aerosol processes. We find that limiting the allowed size ranges of the modes, and subsequent remapping of the distribution, leads almost always to an underestimation of cloud droplet number concentrations (by up to $100 \%$ ) and an overestimation of light extinction (by up to $20 \%$ ). On the other hand, the aerosol-cloud interaction parameter can be either over- or underestimated by the reallocating model, depending on the conditions. For example, in the case of atmospheric new particle formation events followed by rapid particle growth, the reallocation can cause on average a $10 \%$ overestimation of the ACI parameter. Thus it is shown that the reallocation affects the ability of a model to estimate aerosol climate effects accurately, and this should be taken into account when using and developing aerosol models.
\end{abstract}

\section{Introduction}

Atmospheric aerosol particles are one of the most important climate forcing agents affecting Earth's radiative balance directly by scattering and absorbing solar radiation and indirectly by acting as condensation nuclei for cloud droplets (Forster et al., 2007). In order to estimate these effects more reliably, aerosol microphysics have been implemented in global climate models. Atmospheric aerosol particles are highly variable in their size and composition, which strongly influences their radiative effects. Thus capturing the climate effects of atmospheric particles accurately requires detailed modelling, which is limited by the high computational costs.

There are several ways to represent the aerosol size distribution in global climate models. Computationally, the least expensive approach is the so-called bulk method, in which only the mass of different aerosol compounds is tracked and all relevant parameters are calculated assuming a prescribed size distribution (Salil et al., 2012). However, the accuracy of this approach is severely limited. One of the most accurate, but computationally most expensive, methods is the sectional approach, which divides the size range of aerosol particles into discrete size sections. With the sectional method, the accuracy increases by increasing the number of sections. This also leads to an increased number of model tracer variables and thus to a higher computational burden, which can become infeasible to be used in large-scale models. The modal method offers an intermediate level of sophistication for describing the aerosol size distribution. It has been noticed through empirical studies that the sum of log-normal 
a) Original distribution

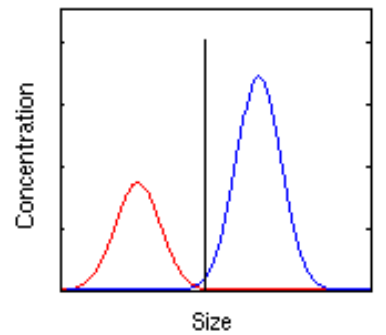

b) After growth

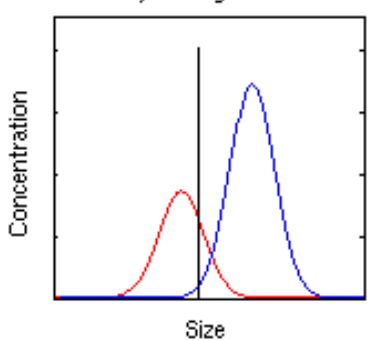

c) Reallocation

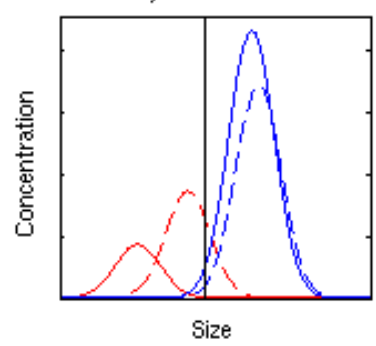

Fig. 1. Schematic figure illustrating the growth of a mode over its threshold diameter, which leads to reallocation of the mode and to a decrease in its mean diameter and total number concentration. The solid vertical line denotes the threshold diameter. At (c) the dashed line corresponds to the size distribution after growth (solid line in $\mathbf{b}$ ).

distribution functions often match well the observed ambient aerosol size distributions (Seinfeld and Pandis, 2006). Therefore the log-normal mode assumption is frequently used in atmospheric applications. When the number of modes is kept low, a modal model is computationally efficient but the model accuracy may become compromised (Liu et al., 2012). In a modal model the aerosol distribution can be represented, for example, by four modes covering the size range from nucleation $\left(D_{\mathrm{p}}<10 \mathrm{~nm}\right)$ to coarse $\left(D_{\mathrm{p}}>1 \mu \mathrm{m}\right)$ sizes (each mode can include several compositions to account for internal mixing) with additional parallel modes to take into account external mixing (Vignati et al., 2004). Each mode can be described by using the number and mass of particles as prognostic variables, and then the average particle diameter can be derived from these variables if the mode standard deviation and composition (densities and mass concentrations of particle phase components) are known. The modal method is the most commonly used method in aerosol-climate models which explicitly describe the aerosol size distribution (Whitby and McMurry, 1997; Ghan et al., 2001; Stier et al., 2005; Bauer et al., 2008; Liu et al., 2012; Mann et al., 2010; Pringle et al., 2010; Vignati et al., 2010; Zhang et al., 2012).

Modal and sectional methods have been compared earlier in several publications (Seigneur et al., 1986; Zhang et al., 2002, 1999; Harrington and Kreidenweis, 1998; Kokkola et al., 2009). This study focuses on the numerical phenomena often connected to the application of modal representation of aerosol distribution in global atmospheric models. More specifically, we investigate the effects of particle reallocation between modes on cloud droplet number concentration, aerosol-cloud interaction parameter and light extinction coefficient in atmospherically relevant scenarios. Particle reallocation effectively means transferring particles between the log-normal modes in specific conditions, in an attempt to achieve more accurate aerosol models. In the following, we introduce some common cases which require the use of this technique and discuss some of its limitations.
In global models, the atmosphere is usually represented with a 3-D (Gaussian) grid. To illustrate why particle reallocation is necessary in global models that use the modal aerosol approach, we consider what happens when aerosol number and mass for a given mode are advected across the border between neighbouring grid boxes. After advection, the updated number and mass mixing ratios in each grid box represent the sum of the pre-existing and transported (from the adjacent grid box) number and mass, and together determine the updated particle size for the mode. When the neighbouring grid boxes have mode diameters of similar size, the resulting combined mode represents the actual physical situation adequately. But if the transported mode has grown significantly compared to the corresponding pre-existing mode in the grid box (or vice versa), the updated mode represents the average of the two populations, generating a peak in number at the new mode diameter, with quite different size distribution than in either of the neighbouring grid boxes.

This misrepresentation is reduced when the diameters of corresponding modes in different grid boxes are not allowed to deviate too much. This can be done by restricting their allowed size ranges with a lower and an upper threshold diameter. When the upper tail of a mode (tail that represents the largest particles) grows past the upper threshold diameter, the mass and number corresponding to the fraction exceeding the threshold diameter are transferred to the adjacent larger mode (Binkowski and Roselle, 2003). Reallocating a large amount of mass but a small number of particles efficiently decreases the average radius of the smaller mode, since the mass to number ratio of the transferred particles is clearly higher than that of the average particle in the mode. The larger mode also decreases in diameter but only slightly due to receiving a rather small amount of mass (and number) compared to the average particle in the mode.

While the use of a reallocation routine prevents unrepresentative distributions when combining modes, it can introduce unphysical changes to the aerosol size distribution, for example by creating minima where none should occur. This is illustrated in Fig. 1. The smaller mode (red curve) grows from a to $b$, and the upper logarithmic tail of the mode 
exceeds the threshold diameter at the vertical line. Then, mass and number corresponding to the largest particles in the smaller mode are moved, i.e. reallocated, to the larger mode (blue curve). In the last panel the dashed line shows the distribution after the growth and the solid line is the result of a reallocated distribution. In reallocation the total aerosol number and mass concentrations are conserved. These are the two parameters that are often studied when model accuracy is evaluated (e.g. Zhang et al., 1999; Mohs and Bowman, 2011). However, the shapes of the overall multi-modal size distributions are distinctly different between the reallocating and unrestricted models. The difference may have a strong effect on physically important aerosol properties, which rely on the number and size of the aerosol particles. Such properties are for example the cloud droplet number concentration, the aerosol-cloud interaction parameter describing the aerosol indirect effect, and the extinction coefficient contributing to the aerosol direct effect.

For example, consider the situation presented in Fig. 1 in a case when the size of the smallest particles activating to cloud droplets is close to the threshold diameter between the modes (i.e. the minimum in the distribution in the reallocating case). In such a situation, the number of cloud droplets formed in the reallocating case is relatively insensitive to variation in maximum supersaturation, whereas the number of droplets forming from the original distribution would be highly sensitive. It is worth noting that in marine stratocumulus regions there can be a local minimum in the number concentration at the activation diameter size (the so-called Hoppel gap; Hoppel et al., 1994). However, in the reallocating model the minimum is in the correct size only if the threshold diameter is set to the Hoppel gap range. Depending on the details of the size distribution, reallocation can cause over- or underestimation of the cloud droplet concentration. It is worth noting that although the absolute CDNC (cloud droplet number concentration) could be wrong, the ACI (aerosol-cloud interaction) could be correctly estimated by different models. In such a case the first indirect aerosol effect could be correctly estimated even if there is some error in the absolute CDNC. In this paper, we carry out box model simulations with modal and sectional aerosol schemes to quantify the impact of reallocation on CDNC, ACI parameter, and mid-visible light extinction.

\section{Methods}

While the problems described above arise predominantly in global models, we studied them in a box model framework, which allows better control over the physical, numerical and statistical phenomena compared to a global modelling framework. Most importantly, the box model allows the use of unrestricted mode structure with minimal errors in contrast to a three-dimensional framework where, e.g. aerosol transport between different model grids would be problematic for an unrestricted structure (Jacobson, 2005). It has to be noted that the errors caused by reallocation are more pronounced in a box model than in large-scale atmospheric models. In three-dimensional framework of large-scale models, processes such as transport and deposition will strongly affect the aerosol size distribution thus reducing the contribution of reallocation to the size distribution.

The main tool of this study was a modal model which describes the aerosol size distribution with 4 modes, and accounts for nucleation, condensation, coagulation and water uptake. The modal model was run using two approaches. In the first approach, we let the model run with unrestricted modes, i.e. there was no reallocation between the modes (hereafter: unrestricted model). In the second approach, we reallocated the modes so that none of them exceeded their set threshold values (hereafter: reallocating model). The threshold diameters used for reallocation were 10, 100, and $1000 \mathrm{~nm}$ for nucleation, Aitken and accumulation modes, respectively. These values fall in the range of values typically used in large-scale atmospheric models. Note that these are not the limits for the average diameter but instead to the upper logarithmic tail of the mode. When a predefined (often very small) fraction of the mode's mass exceeds the threshold diameter, that mass along with the corresponding particle number is reallocated to the larger adjacent mode. Note the difference between the threshold diameter and the largest mean diameter which can be reached by the mode without its upper tail exceeding the threshold diameter.

In addition to the modal model, we also used the sectional model SALSA (Kokkola et al., 2008). This sectional model was run with a high size resolution using 100 size sections, and thus it served as a reference model when analysing the effects of reallocation on climate relevant properties (CDNC, ACI, $b_{\text {ext }}$ ). SALSA modelled the same physical processes as the modal models.

Although the unrestricted modal model is not used in global applications, results from it were also compared against the sectional model. This was done in order to determine the extent to which the difference between reallocating and sectional models can be explained by reallocation and to which extent simply by differences in modal and sectional size distributions.

The number of activated aerosol particles during cloud formation was calculated using the aerosol activation parameterisation of Nenes and Seinfeld (2003). In the parameterisation, sulfate was assumed to have chemical properties of ammonium sulfate. The extinction coefficient was calculated using the libRadtran library for radiative transfer calculations (Mayer and Kylling, 2005). The extinction was calculated for a wavelength of $550 \mathrm{~nm}$. The composition of aerosol particles for the light extinction calculations was $30 \%$ sulfate, $70 \%$ water. The refractive indices for sulfate and water were $1.43+1 \times 10^{-8} i$ and $1.33+2.00001 \times 10^{-7} i$. The ACI parameter was determined by 
$\mathrm{ACI}=\frac{\mathrm{d} \log (\mathrm{CDNC})}{\mathrm{d} \log (N)}$,

where $N$ is the total aerosol number concentration (McComiskey et al., 2009; Ahmad et al., 2013).

In experiments that simulated new particle formation, nucleation was calculated using activation type nucleation ( $\mathrm{Si}$ hto et al., 2006),

$J=A\left[\mathrm{H}_{2} \mathrm{SO}_{4}\right]$,

where $J$ is the rate of $1.5 \mathrm{~nm}$ particles formed, $A$ is the nucleation coefficient and $\left[\mathrm{H}_{2} \mathrm{SO}_{4}\right]$ is the sulfuric acid concentration. The coefficient $A$ is determined from measurements, and in our simulations the used value of $10^{-6} \mathrm{~s}^{-1}$ corresponds to a value obtained for boreal forest nucleation events. The gas phase sulfuric acid concentration has a sink due to new particle formation and condensation as in Vignati et al. (2004). The detailed description of the sectional model that was used as a reference model can be found in Kokkola et al. (2008). All simulations included only sulfate particles, gas phase sulfuric acid and water.

Since this is a comparison between different models with known limitations, we chose relative difference,

Relative difference $(a, b)=\frac{a-b}{(a+b) / 2}$,

as our metric since it does not assume either of the values $a$ or $b$ as an absolute reference. In this study, we did four different experiments to address typical situations arising in global models in which size distribution dependent parameters can be affected by the particle reallocation. The first three experiments had the same trimodal background aerosol with mean diameters of 30,200 and $2400 \mathrm{~nm}$ and number concentrations of 500, 200 and $0.1 \mathrm{~cm}^{-3}$, respectively. The geometric standard deviation was assumed 1.59 for all modes. This distribution of the background aerosol has been found representative of boundary layer conditions (Asmi et al., 2011). To ensure the comparability between the modal and sectional models, all CDNC, ACI and $b_{\text {ext }}$ (light extinction coefficient) calculations were done with the sectional version of the cloud activation parameterisation and library functions by transforming the log-normal modes to a sectional representation with 100 sections. With this high resolution the errors from the transformation were negligible.

\section{Results}

\subsection{Emission reallocation}

The motivation for the first experiment was to study how the reallocation can affect the aerosol size distribution when primary aerosols are emitted (only source of particles in this experiment). Emission databases for anthropogenic primary aerosol typically provide only particle mass fluxes; however, models explicitly tracking the aerosol size distribution need to assume also the size for the emitted particles. Here we use a unimodal emission size with an $80 \mathrm{~nm}$ geometric mean diameter $\left(D_{\mathrm{p}}\right)$ and a geometric standard deviation $(\sigma)$ of 1.8 , as recommended by Dentener et al. (2006) for biofuel, wildfire and volcanic emissions. With these recommended values, the mean diameter of the emitted particles is fairly close to the commonly assumed threshold diameter for reallocation and thus the artificial minimum produced by the reallocation procedure. The emission is introduced to the system as a lognormal mode and before any calculation it is merged with the already existing aerosol distribution. Since reallocation from the Aitken to the accumulation mode happens when the Aitken mode average diameter is larger than $\sim 30 \mathrm{~nm}$, emitting particles of $80 \mathrm{~nm}$ diameter into this mode causes strong reallocation of the emitted particle mode between Aitken and accumulation modes.

During the experiment, the CDNC and ACI parameters were calculated for a variety of emission mode number concentrations $\left(50-800 \mathrm{~cm}^{-3}\right)$ and updraft velocities $(0.1-$ $\left.3.0 \mathrm{~m} \mathrm{~s}^{-1}\right)$. A wide velocity range was chosen to encompass scenarios from marine stratocumulus to convective clouds (Cotton and Anthes, 1989). Since $b_{\text {ext }}$ is independent of the updraft velocity, the relative difference for it was calculated only as a function of emission number concentration. The emission mode's mean diameter was kept constant (at the emission inventory value) and the same calculations were done with and without pre-existing background aerosol. This experiment did not include any aerosol processes, only reallocation of the distribution followed by calculations of CDNC, ACI and $b_{\text {ext }}$. We present only a comparison between the reallocating modal model and the sectional reference model, since the unrestricted modal model gives practically identical results to the reference model now that no aerosol microphysics is simulated.

Absolute cloud droplet number concentrations depicted in Fig. 2, Fig. 3 shows the relative difference in CDNC as a function of the emission concentration and updraft velocity for both the reallocating and unrestricted models. The reallocation of the emission mode causes an underestimation of the CDNC, especially for lower updrafts, of up to $50 \%$ without background, and with background aerosol up to almost $40 \%$. The activated fractions vary from 48 to $98 \%$. The underestimation of the CDNC due to reallocation occurs for the following reason: the reallocation transfers the majority of the aerosol number originally in the emission mode to the Aitken mode, which in our setup means that most of them become smaller than the critical diameter for cloud activation (schematic illustration in Fig. 4). On the other hand, the original emission mode diameter is of similar size than the critical diameter. This means that reallocation reduces the number of particles larger than the critical diameter (which defines the CDNC). The difference is further enhanced by low updraft 

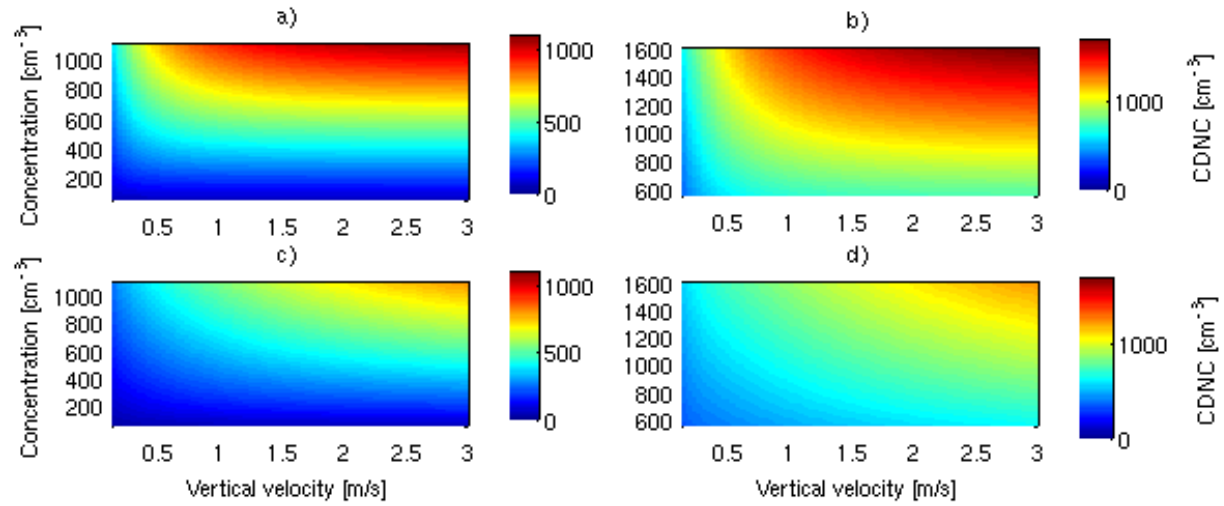

Fig. 2. The absolute cloud droplet number concentrations from the first experiment. (a) and (c) show the CDNCs for unrestricted and reallocating modal models for the no background case. Panels (b) and (d) for the case with background aerosol.
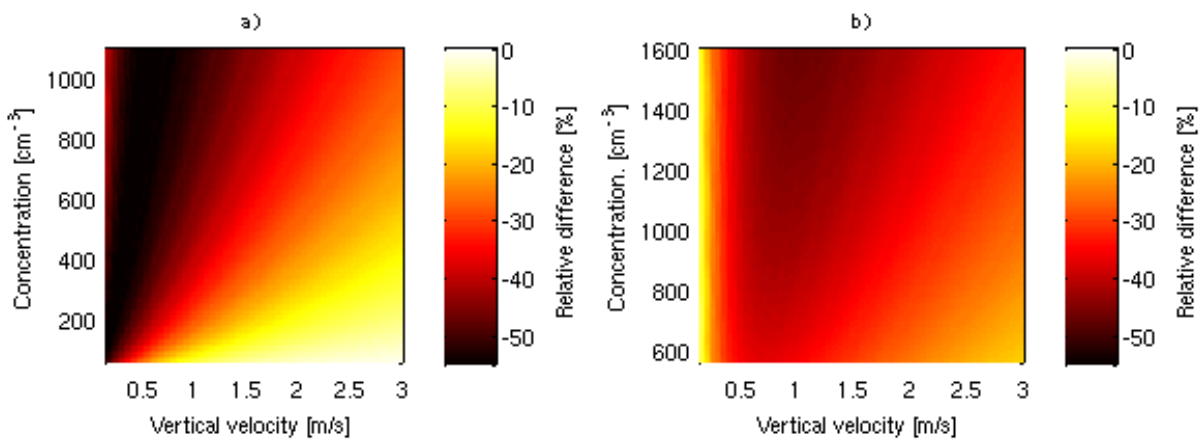

Fig. 3. Relative difference of the CDNC between the reallocating and unrestricted modal models in experiment 1 . (a) shows the difference without and (b) with background aerosol.

velocities (corresponding to large critical diameters), as in the unrestricted model some of the particles in the emission mode still activate but in the reallocated model practically all emitted particles transferred to the Aitken mode remain unactivated. With an increasing vertical velocity the critical diameter decreases and thus also particles that are in the Aitken mode begin to contribute to the $\mathrm{CDNC}$, which decreases the underestimation.

When background aerosol is included in the simulation, the underestimation decreases (Fig. 3b). This is because the background accumulation mode particles decrease the relative contribution of the emitted particles to the CDNC. It is worth noting that if the critical diameter and the mean diameter of the background accumulation mode were larger than the emission mode, the reallocation would cause an overestimation of CDNC (not shown in figures). This would happen because some of the emitted particles are reallocated to the accumulation mode which is (at least partly) activated, whereas in the unrestricted distribution would not contribute to the CDNC. This effect is weaker when the background aerosol is excluded in the simulation because the accumulation mode after reallocation now has a smaller diameter compared to the case with background aerosol. This is because the large background mode particles dominate over the clearly smaller reallocated particles, and thus the addition of the reallocated particles decreases the accumulation mode diameter only slightly when background aerosol is included.

In Fig. 5 the relative difference of the ACI parameter shows both over- and underestimation by the model with reallocation compared to the freely moving (i.e. unrestricted) model, depending on the concentration of emitted particles and the updraft velocity. For updraft velocities below $0.4 \mathrm{~m} \mathrm{~s}^{-1}$ and without background aerosol, reallocation causes overestimation in the ACI parameter while underestimating it for higher updraft velocities. With background aerosol, the switch between over- and underestimation occurs approximately at $0.8 \mathrm{~m} \mathrm{~s}^{-1}$. These results indicate that ACI would be overestimated in the marine stratocumulus clouds, which typically have relatively low updrafts, and underestimated in other cloud types which have higher updraft velocities. The maximum relative differences in ACI between the reallocated and unrestricted models were $+25 \%$ and $-20 \%$ without background aerosol. With background aerosol, the relative differences were $+19 \%$ and $-16 \%$. The absolute values for the ACI parameter in the two modal model versions varied between 0.58 and 0.98 . The latter 


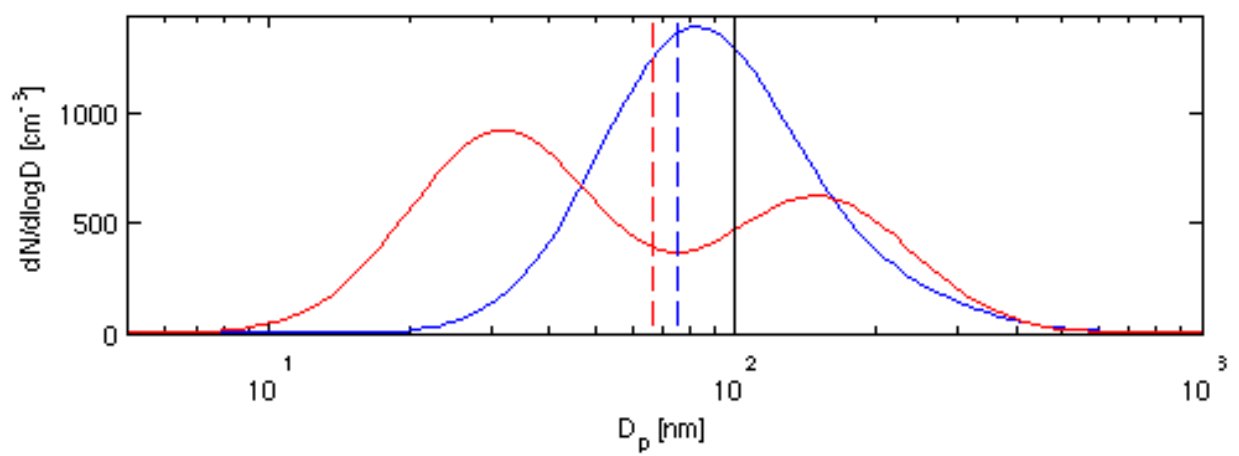

Fig. 4. Schematic figure explaining the effects of reallocation to particle activation. Blue line is the emission mode, which is then reallocated into Aitken and accumulation modes (red curve). Dashed lines are the respective critical diameters for unrestricted and reallocating models and the solid black is the threshold diameter for Aitken mode. There is no background aerosol present.
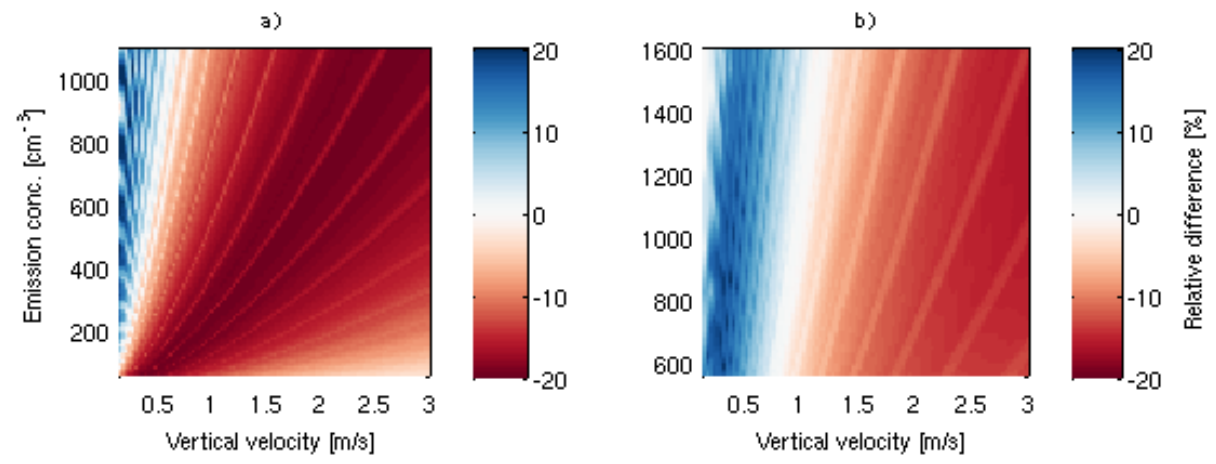

Fig. 5. Relative difference of the ACI parameter between the reallocating and unrestricted modal models in experiment 1 . (a) shows the difference without and (b) with background aerosol.

rather high value was found for the unrestricted model at the maximum updraft velocity and with a low number of particles.

The reason behind the behaviour of the ACI parameter is fundamentally the same as above for CDNC. A significant fraction of the particle number in the emission mode in the unrestricted model is above the critical diameter (Fig. 4), whereas the reallocation moves the majority of the particles below the critical diameter. Because of this, the emission mode in the reallocating model is unable to contribute as directly to the CDNC as in the unrestricted model. This means that the ACI parameter (Eq. 1) is higher in the unrestricted model compared to the model with reallocation.

Including a background aerosol decreases the ACI parameter, but in the setup investigated here more effectively in the unrestricted than in the reallocating model. This is because the presence of a non-activating background Aitken mode decreases the activated fraction in the unrestricted model more than in the reallocating model, which in turn decreases the CDNC sensitivity to changes in total number concentration.

In this emission experiment, the small size of the emitted particles does not cause strong (mid-visible) light extinction. The maximum value for the extinction coefficient was below $2 \mathrm{Mm}^{-1}\left(=2 \times 10^{-6} \mathrm{~m}^{-1}\right)$ without background aerosol. The relative difference in the $b_{\text {ext }}$ between the reallocating and unrestricted models was approximately a constant $38 \%$, but low absolute values decreased its relevance. With background aerosol, the absolute values were between 10 and $13 \mathrm{Mm}^{-1}$ but the relative difference was just above $5 \%$.

\subsection{Constant emission into an aging aerosol distribution}

In the second experiment, we studied how the reallocation of particles affects model results in a case with constant aerosol emission and the aerosol size distribution evolving due to microphysical processes. The microphysical processes affecting the size distribution were coagulation, growth by water uptake, and sulfuric acid condensation; however, nucleation was excluded from this experiment. These processes acted upon the background size distribution detailed in Sect. 2.1. The second experiment was ran over $18 \mathrm{~h}$ for updraft velocities from 0.1 to $3.0 \mathrm{~m} \mathrm{~s}^{-1}$ assuming a constant emission rate of $0.01 \mathrm{~s}^{-1} \mathrm{~cm}^{-3}$ and emission mode mean diameter of $80 \mathrm{~nm}$. After $1.5 \mathrm{~h}$ from the start of the simulation, the emission of $\mathrm{H}_{2} \mathrm{SO}_{4}$ was introduced to the system. The production 
a) Reallocating vs unrestricted

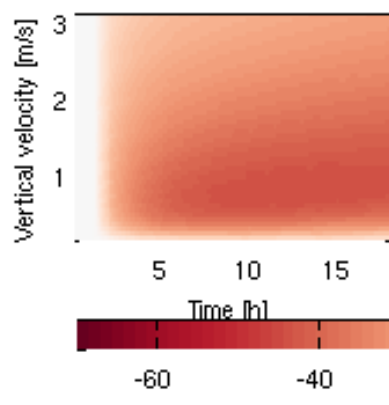

b) Reallocating vs sectional

3

2

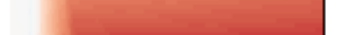

1

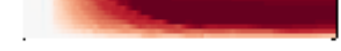

5

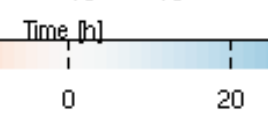

20

20 c) Unrestricted vs sectional

3

2

1

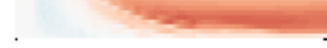

$5 \quad 10 \quad 15$

Time [h]

$40 \quad 60$

Fig. 6. Relative difference of the cloud droplet number concentration between the three models in experiment 2.

rate $\left(P_{\mathrm{SA}}\right)$ of $\mathrm{H}_{2} \mathrm{SO}_{4}$ into the system was defined by

$P_{\mathrm{SA}}=P_{0} \frac{T-t}{T}$,

where $P_{0}$ was a constant rate of $5.2 \times t 10^{7} \mathrm{~cm}^{-3} \mathrm{~s}^{-1}$, and $T$ and $t$ were the total simulation time (i.e. $18 \mathrm{~h}$ ) and the current time (in hours) at a given time step. So the amount of $\mathrm{H}_{2} \mathrm{SO}_{4}$ added to the system was linearly decreasing through the simulation. In addition, the explicitly resolved condensation and new particle formation decreased the $\mathrm{H}_{2} \mathrm{SO}_{4}$ vapor phase concentration. We calculated the relative difference in $b_{\text {ext }}$ between the unrestricted and reallocating modal approaches as a function of simulation time. In addition, we calculated the relative differences in CDNC and the ACI parameter for a range of updraft velocities. These results were also compared with the sectional model.

Figure 6 shows the relative difference of the CDNC between the different models. With a constant emission rate of 0.01 particles per second (average diameter $80 \mathrm{~nm}$ ), the reallocating model underestimates the CDNC for the most part compared to the unrestricted modal and sectional models. The largest difference of $-77 \%$ is between the reallocating and sectional models, whereas the unrestricted model underestimates at maximum by $-41 \%$ compared to the sectional model. At low updraft velocities and in the beginning of the simulation the unrestricted and reallocating modal models overestimate the CDNC compared to the sectional model by up to 9 and $5 \%$, respectively. This is because the largest particles in the Aitken mode in the modal models grow faster to activation sizes compared to the sectional model. Since the mode width in the modal model is fixed, the rapid growth of small particles also affects the larger particles in the same mode, causing a too-fast growth rate. In contrast, in the sectional model different sections in the same mode grow independently of other sections.

Figure 6 also illustrates a noticeable difference between a modal model with fixed mode width and a sectional model. As the shape of a "mode" is allowed to change freely in the sectional model, the condensational growth will narrow it quickly due to small particles growing faster compared to larger ones. This also shows up in cloud activation as a sharp increase in the CDNC when the narrow peaked "mode" reaches the critical diameter. This increase can be seen in Fig. 6 as a sharp gradient in panels $b$ and c. Note also that the average diameter of the Aitken mode in the modal models increases not only by condensation (contributing $25 \mathrm{~nm}$ to the growth of the particle diameter during the $18 \mathrm{~h}$ ) but also by the addition of mass from the emitted particles to the Aitken mode (contributing to the growth by additional $45 \mathrm{~nm}$ ). However, after the Aitken mode diameter has reached the size of the emission mode, condensation is not strong enough to increase the mode diameter further since the injection of $80 \mathrm{~nm}$ particles will dominate the average diameter compared to already slowed down condensational growth.

The relative difference of the ACI parameter is shown in Fig. 7. The relative difference between the modal models goes from a maximum of $23 \%$ (updraft velocity $\sim 0.4 \mathrm{~m} \mathrm{~s}^{-1}$ ) to a minimum of $-16 \%$ (updraft velocity above $1.5 \mathrm{~m} \mathrm{~s}^{-1}$ ). Compared to the sectional model, the modal models overestimate the ACI by close to $100 \%$ before the narrow (and high) Aitken mode in the sectional model reaches the activation diameter. However, once this narrow Aitken mode has grown to the activation size, the modal models start to underestimate the ACI. The underestimation is up to $25 \%$ by the reallocating and up to $10-20 \%$ by the unrestricted model. The relative differences of the $\mathrm{CDNC}$ and $\mathrm{ACI}$ parameter are for the large part governed by the same phenomena as explained and illustrated in Sect. 3.1 and Fig. 4.

Figure 8 shows the relative difference in the light extinction coefficient between the models. At the end of the simulation the relative difference is $4 \%$ between the unrestricted and the sectional model and $8 \%$ between the reallocating and the sectional model. The extinction coefficient is sensitive to particles which are significantly larger $(\sim 500 \mathrm{~nm})$ than the critical activation diameter $(\sim 100 \mathrm{~nm})$. In the reallocating model, reallocation increases the number of those large particles. While the sectional model does have more particles above the critical diameter than the modal models, it does 


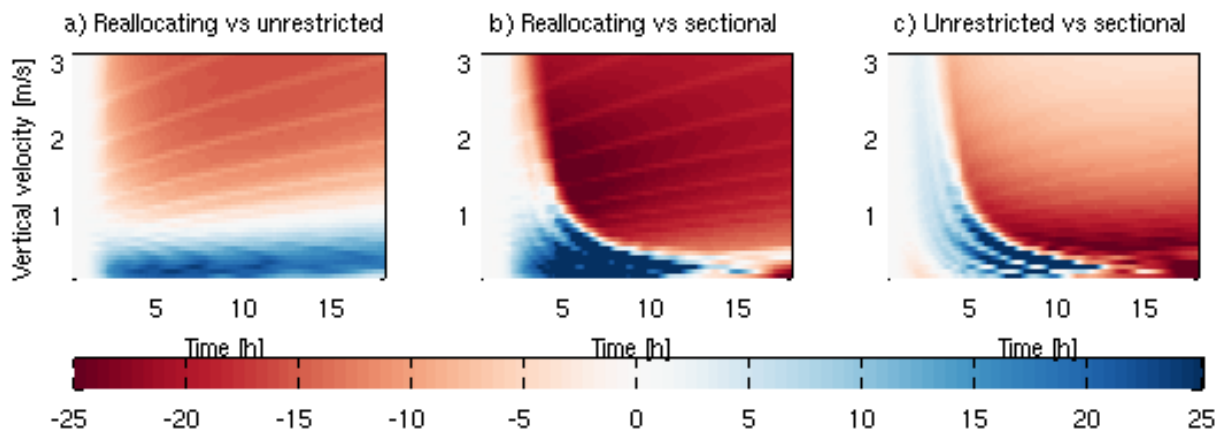

Fig. 7. Relative difference of the cloud-aerosol interaction parameter between the three models.

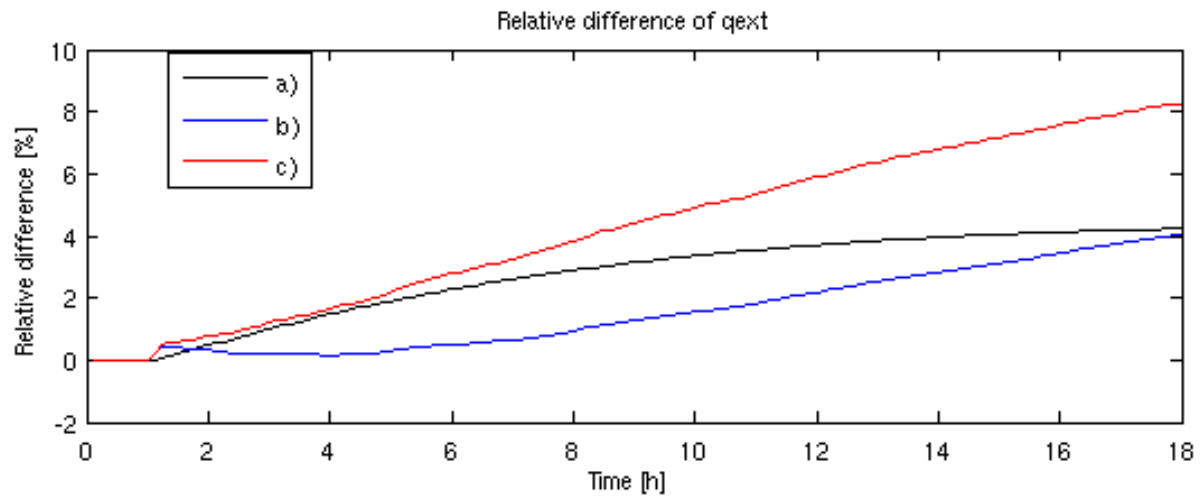

Fig. 8. The relative difference of the light extinction coefficient. In the legend (a) stands for comparison between reallocated and full moving models, (b) for full moving vs. sectional and (c) for reallocated vs. sectional models.

not have significantly more particles above the sizes sensitive to light scattering and absorption. The absolute values for the extinction coefficients were $150-250 \times 10^{-6} \mathrm{~m}^{-1}$.

\subsection{Nucleation event}

The third experiment simulated all microphysical processes, nucleation being the only mechanism increasing the particle number concentration. Again, the simulation was initialised with the background size distribution detailed in Sect. 2.1. Sulfuric acid was injected continuously (maximum concentrations of $5.0 \times 10^{8} \mathrm{~cm}^{-3}$ ) to the system starting at $1.5 \mathrm{~h}$ into the simulation until the end of the simulation $(18 \mathrm{~h})$. The CDNC, ACI parameter and $b_{\text {ext }}$ were compared between the unrestricted and reallocating modal models and the sectional model for updraft velocity range of $0.1-3.0 \mathrm{~m} \mathrm{~s}^{-1}$. In all of the simulations, the average diameters of the background modes did not exceed their reallocation threshold values, making sure that there was no need for reallocation of the background distribution at the beginning of the simulations.

Figure 9 shows a significant difference in the number size distribution between the unrestricted and reallocating modal representations and the sectional aerosol representation. Note the persistent minima in the size distribution of the reallocating modal model caused by reallocation (Fig. 9b).

Both the unrestricted and sectional models have a large number of particles in the growing nucleation mode throughout the simulation, whereas in the reallocating model the particles are being divided between two or three modes. As seen in Fig. 9, the location of the minima and maxima in the size distribution in relation to the critical size (a typical value illustrated in the figure with a horizontal dashed line) is crucial in terms of particle activation. Also in a modal model, a fixed mode width causes the largest particles in a mode with a small average diameter to artificially grow faster than particles of the same size in a sectional distribution. This is because the small particles within the mode have a higher growth rate compared to larger particles and the contribution of these quickly growing particles to the mass of the mode also increases the size of the larger particles by increasing the average diameter. In the sectional distribution, the simulated particle mode tends to narrow significantly due to the faster growth rate and coagulation loss of the smallest particles. When the narrow peak in the sectional model reaches the activation size it produces significantly more cloud droplets when compared to both modal representations. 


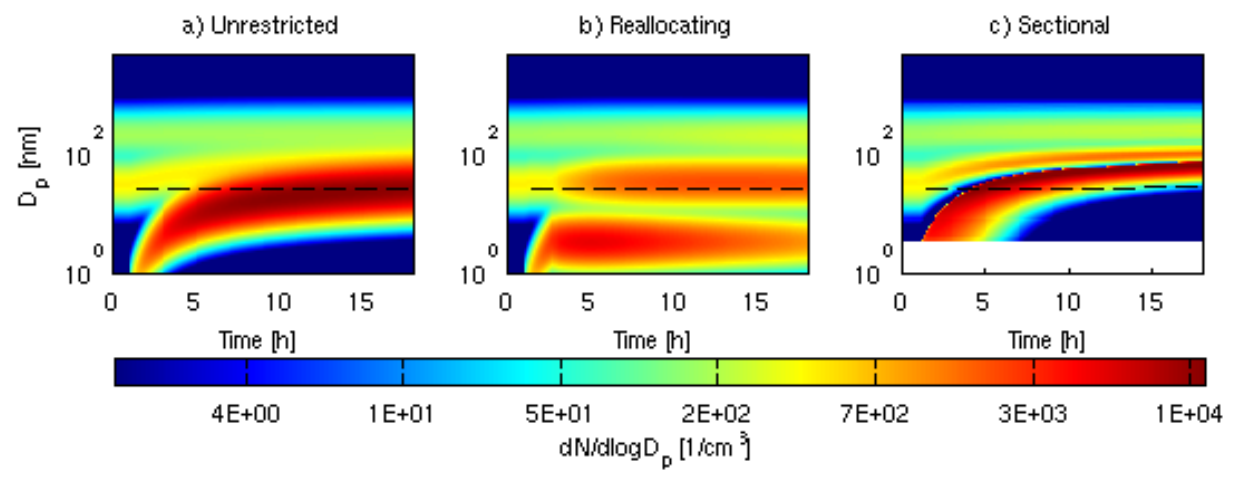

Fig. 9. Number size distribution plots illustrating the major differences between the models. An example of a critical diameter for a midrange updraft velocity is plotted with dashed line on the distributions.

a) Reallocating vs unrestricted

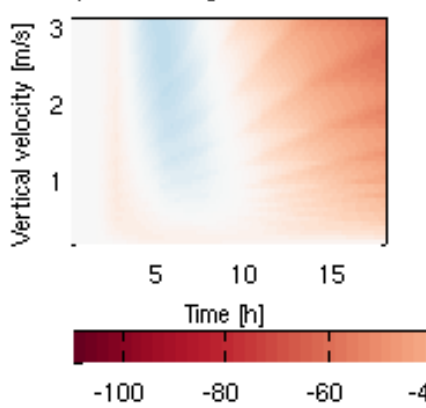

b) Reallocating vs sectional

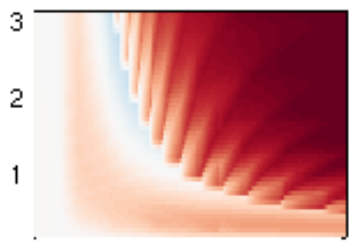

$5 \quad 10 \quad 15$ c) Unrestricted vs sectional

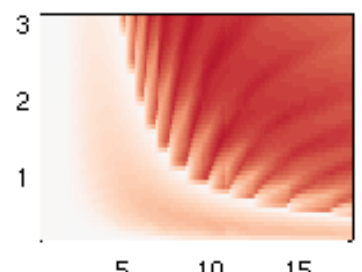

$5 \quad 10 \quad 15$
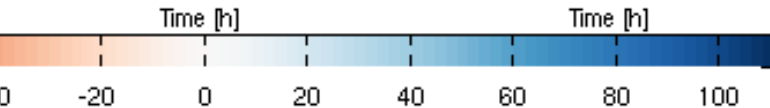

Fig. 10. Relative difference of the CDNC between the three models. Notice the small area of overestimation by the reallocating model compared to the unrestricted model (a).

Due to these reasons, the differences in CDNC and ACI parameter may shift considerably depending on the conditions. Figure 10 shows the relative difference in CDNC between the three models as a function of time and updraft velocity. In Fig. 10a, which shows the difference for reallocating and unrestricted modal models, the critical diameter is within the Aitken mode for updraft velocities above $1 \mathrm{~m} \mathrm{~s}^{-1}$. Between 1 and $4 \mathrm{~h}$ in the simulation, the Aitken mode reaches its threshold diameter in the reallocating model, and thus the mode mean diameter does not grow further. After that the Aitken mode contributes to the increase of CDNC only via reallocation of mass and (small) number to the accumulation mode; this causes increasing underestimation until $4 \mathrm{~h}$. When the particles are being reallocated after $4 \mathrm{~h}$ from nucleation mode to partially activating Aitken mode, the difference between the distributions even out and momentarily the reallocated model produces $20 \%$ more cloud droplets. Eventually the freely growing nucleation mode in the unrestricted model grows enough to contribute to $\mathrm{CDNC}$, whereas a large portion of the nucleated particles in the reallocating model are held back in the nucleation and Aitken modes, which eventually leads to underestimation $(-40 \%)$ by the reallocating model compared to the unrestricted model. Figure $10 \mathrm{~b}$ and $\mathrm{c}$ show that after the narrow nucleation mode in the sectional model has reached the activation size, it produces $118 \%$ more droplets than the reallocating model and $87 \%$ more than the unrestricted modal model. By comparing these two numbers, it is evident that the fixed mode width (inherent in both versions of the modal model) causes a relatively larger error in CDNC than reallocation when nucleated particles are large enough to form cloud droplets in the sectional model.

It is also worth pointing out that the differences in the number size distributions also affect the coagulation loss of the particles. In the reallocating model version, more particles remain in the nucleation mode (compared to unrestricted modal and sectional models) which leads to higher average coagulation coefficients and thus higher particle loss by coagulation. In this experiment the largest relative difference between the unrestricted and reallocating model versions' total number concentration was $40 \%$, which also amplifies the underestimation of the CDNC by the reallocating model.

The relative differences of the ACI parameter (Fig. 11) show the same patterns, but mostly of the opposite sign, as was seen for the relative differences of the CDNC. This is due to the fact that new particle formation creates a distinct peak in the size distribution in the sectional model and strongly limits the CDNC and its sensitivity to changes in particle concentration, when the peak is below critical diameter. This 


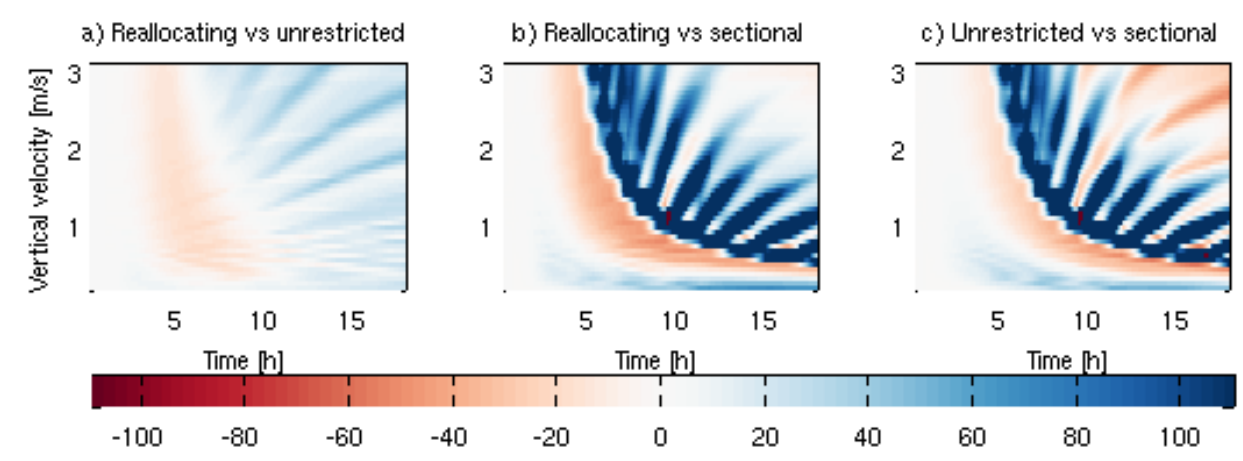

Fig. 11. The relative difference of the ACI parameter between the three models. The sharp mode in the sectional distribution together with the changes in the critical diameter cause the extreme differences compared to the modal models with fixed mode width.

strongly decreases the fraction of activated particles thus leading to lower ACI parameter values. In fixed width modal models this effect is not so pronounced and thus strong overestimation by modal models in comparison to the sectional one can be seen.

The difference in particle number concentrations for particles with diameter of the order of a few hundred nanometres (to which the $b_{\text {ext }}$ is sensitive to) was not significant in this experiment between the different models. This results in small relative differences ranging from 7 to $-6 \%$ in the extinction coefficient between the models as can be seen in Fig. 12.

\subsection{Ensemble nucleation event}

To analyse the effect of the simulation conditions on the full microphysics run, we made simulations for conditions where the model produced nucleation events with a large number of different conditions. The number concentrations for the initial size distribution of the Aitken mode varied between 100 and $6400 \mathrm{~cm}^{-3}$. For the initial accumulation mode the number concentrations varied between 50 and $3200 \mathrm{~cm}^{-3}$. The updraft velocity varied between 0.1 and $3.0 \mathrm{~m} \mathrm{~s}^{-1}$. Although the setup for these simulations was tailored for simulating nucleation events, some of the background distributions acted as such a strong condensation sink for sulfuric acid that there was no noticeable new particle formation (NPF).

Figure 13 shows the relative differences between all three models for an updraft velocity of $1.0 \mathrm{~m} \mathrm{~s}^{-1}$ (one case presented as an example for clarity). For initial accumulation mode number concentrations higher than $1000 \mathrm{~cm}^{-3}$ (red lines), the relative difference in the CDNC between the models is close to zero. This is because condensation to the accumulation mode depletes most of the $\mathrm{H}_{2} \mathrm{SO}_{4}$, and thus the growth of the Aitken mode is weak; therefore very little or no reallocation occurs between the Aitken and accumulation modes. The growth and reallocation of the accumulation mode to coarse mode do not cause a difference in CDNC since both modes are usually larger than the critical diameter. In addition, in these cases with high accumulation mode concentration, there is no new particle formation due to the lack of available sulfuric acid. Increase in the updraft velocity evens out the differences between the models, as with high updrafts most of the particles are be activated.

When there are fewer particles in the accumulation mode (blue and green lines), the underestimation of CDNC by the reallocating model starts to be more pronounced. With a few hundred particles per cubic centimetre in the accumulation mode, the underestimation between the reallocating and unrestricted models is around $60 \%$ at the end of the simulation. Relative differences are similar between the unrestricted and sectional models. The largest relative differences are seen between the reallocating and sectional models with values of approximately $-110 \%$ (in the case of $1.0 \mathrm{~m} \mathrm{~s}^{-1}$ updraft velocity). The overestimation for the reallocating model compared to the unrestricted and sectional ones at the beginning of the simulation is due to the same reasons as in the previous nucleation experiments (nucleation mode is still small in the unrestricted and sectional models while first the particles are reallocated into Aitken mode in the reallocating model).

As seen in the previous experiment in Sect. 3.3, the ACI parameter can be very sensitive to small changes in updraft velocities when there are steep gradients in the size distribution. To show the trend in the ACI parameter, the average relative difference over the 49 size distributions is presented in Fig. 14. The reasons behind the higher values given by modal models compared to the sectional model are the same as in Sect. 3.3. On average, the modal models agree well with each other and the relative difference between the sectional and both of the modal models is around $10 \%$.

Figure 15 shows the relative differences of the extinction coefficient between the different models. The difference between the unrestricted and the sectional model remains relatively small, between 3 and $-5 \%$ because the condensation of sulfuric acid is not fast enough to narrow the accumulation mode and thus the assumption of constant mode width is causing only a small error. The overestimation of $b_{\text {ext }}$ for 


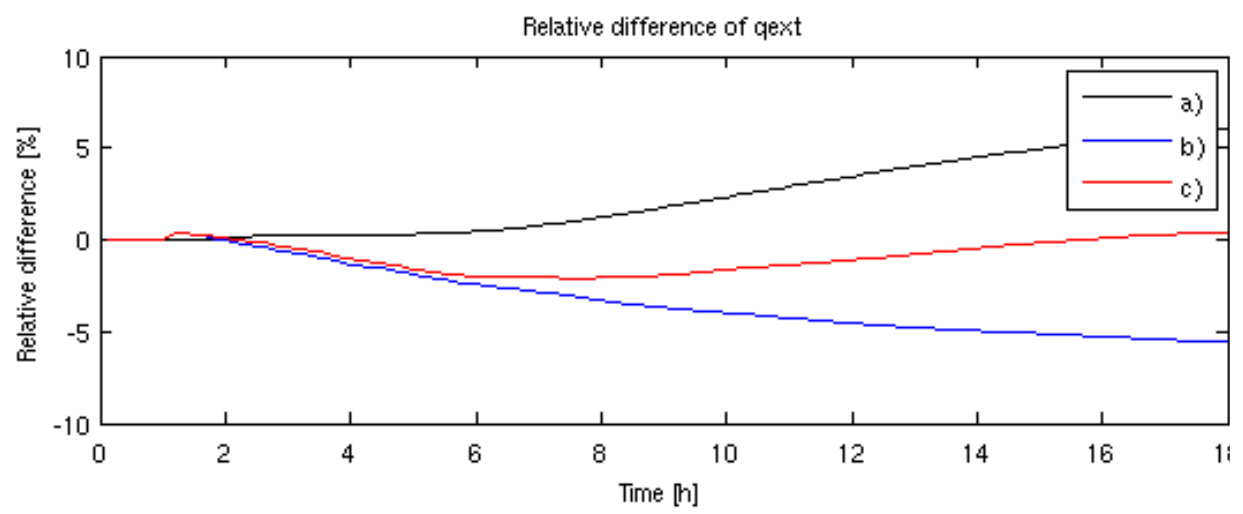

Fig. 12. The relative difference of the light extinction coefficient. In the legend (a) stands for comparison between reallocated and full moving models, (b) for full moving vs. sectional and (c) for reallocated vs. sectional models.

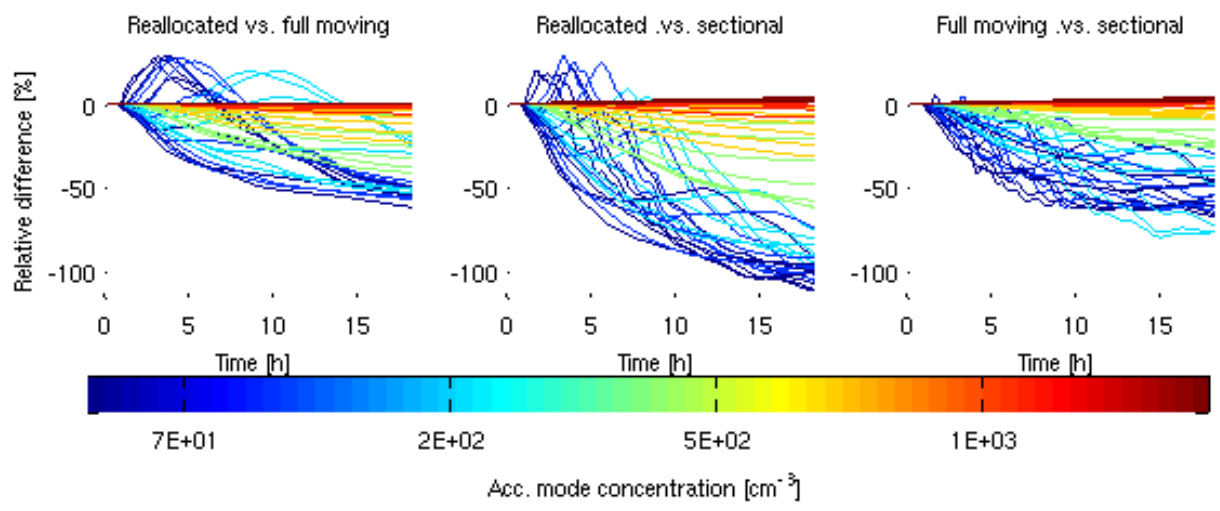

Fig. 13. The relative differences of the CDNC between the three different models. Similar phenomenons can been seen on lower accumulation mode number concentrations as in previous figures.

the reallocating model reaches $20 \%$ when the accumulation mode concentration is at its lowest values. Since the accumulation and coarse mode particles dominate the extinction properties of the droplets, the highest differences occur in a case when the accumulation mode is initially at low concentration, and the concentration is increased only by reallocation of the particles when the growing modes in the unrestricted modal and sectional models are still too small to contribute to the light extinction.

\section{Conclusions}

In this study we concentrated on the effects of reallocating the aerosol mass and number between modes on size dependent aerosol properties. The reallocation is a numerical routine required in global modal aerosol models to keep the aerosol distribution representative of the physical state. More specifically we focused on three atmospherically relevant aerosol properties: cloud droplet number concentration (CDNC), aerosol-cloud interaction parameter (ACI) and light extinction coefficient $\left(b_{\text {ext }}\right)$. We performed four experiments to address the typical aerosol related phenomena in the atmosphere. We compared the results between a sectional model and both reallocating and unrestricted modal models.

In the first experiment we studied the effect of the reallocation on the aerosol properties when primary aerosol emissions with AeroCom recommendations for size distribution were reallocated according to the model setup. We evaluated the relative differences of the aerosol properties as a function of the emission concentration and updraft velocity. The results show a clear underestimation of the CDNC and ACI by the reallocating model compared to the unrestricted modal model/sectional model. Changes in the size distribution were confined to small particle sizes which did not have a noticeable effect on the extinction coefficient. In the second experiment a constant aerosol emission of the same size as in the first experiment was allowed to be modified by microphysical processes, and a similar underestimation of the CDNC was observed between the two versions of the modal model as in the first experiment. Both of the modal models also underestimated the CDNC compared to the sectional model, 
a) Reallocating vs. unrestricted

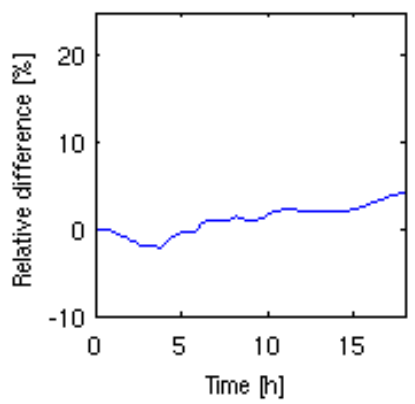

b) Reallocating .vs. sectional

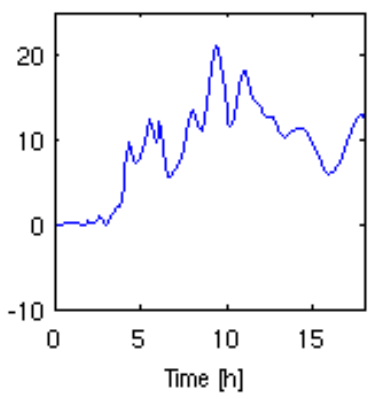

c) Unrestricted .vs. sectional

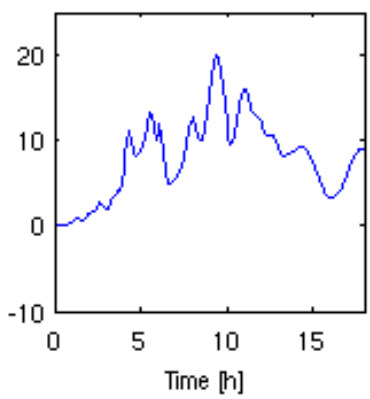

Fig. 14. The relative difference of the ACI parameter presented as mean over the 49 different distributions.

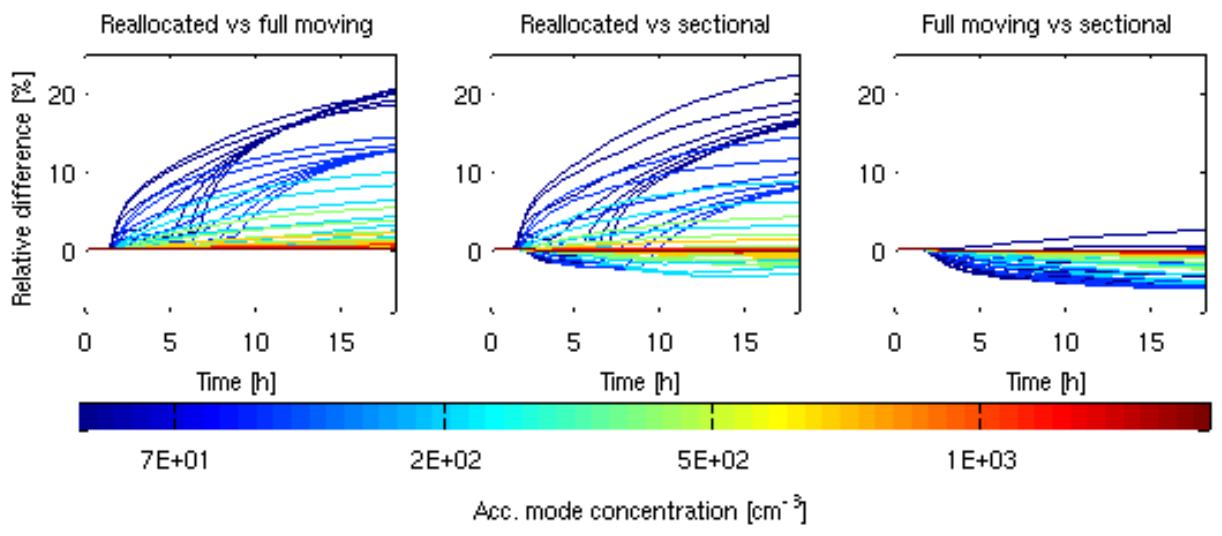

Fig. 15. The relative difference of a extinction coefficient between the three models.

although less in the case of the unrestricted model. In the second experiment, particles also grew large enough to be able to affect the light extinction. The reallocating modal model gave the largest extinction coefficient values followed by the unrestricted model and the sectional model.

The last two experiments included full aerosol microphysics and focused on simulations with new particle formation. First we analysed in detail a single nucleation event with all three models for a range of updraft velocities. Eventually the reallocating model underestimates the CDNC compared to the unrestricted model, which in turn underestimates the CDNC when compared to the sectional model. In this experiment there were no significant differences in the extinction coefficient between the models.

In the last experiment, we assessed the effect of the initial background distribution by using 49 different initial combinations of Aitken and accumulation mode number concentrations for 50 different updraft velocities. For the most part the results agree with the previous experiments. In a small number of cases in which the accumulation mode dominates the total number concentration, the models agree well with respect to CDNC and ACI values. However, in atmospherically more relevant cases, in which the Aitken mode dominates, the underestimation in CDNC by reallocation is again clearly noticeable. The extinction coefficient was overestimated by the reallocating model compared to both the unrestricted and sectional models for all accumulation mode concentrations. On the other hand, the unrestricted and sectional models agreed reasonably well with each other. A similar study by Mann et al. (2012) compared predicted CCN (cloud condensation nuclei) concentrations from a modal and a relatively coarse sectional global model. Their result showed an overestimation by the modal model compared to the sectional model. Although opposite to our findings, the results of these two studies are not directly comparable; our sectional model had a much higher size resolution, the global model setup introduces many new processes (deposition, cloud processing, advection) not considered in our study, and the Mann et al. study addressed CCN (i.e. particles larger than 50 and $150 \mathrm{~nm}$ ) not CDNC.

According to our results, limiting the mode average diameters within given size ranges and the following remapping of the modes by reallocation causes generally an underestimation of cloud droplet number concentration while overestimating the light extinction in modal models. The ACI parameter can be either over- or underestimated by the reallocating model, depending on the conditions. These biases rising from the use of the reallocation approach affect the ability of 
modal models to estimate the aerosol-climate effects accurately: the underestimation of the CDNC after the nucleated particles grow big enough to form cloud droplets causes an underestimation of the first aerosol indirect effect, whereas the overestimation of the extinction will tend to cause a toostrong aerosol direct effect. These findings should be taken into account when using and developing aerosol models.

Acknowledgements. The research has been supported by the strategic funding of the University of Eastern Finland, and by the Academy of Finland Centre of Excellence Program (project no. 1118615).

Hannele Korhonen and Sami Romakkaniemi acknowledge the Academy of Finland for the Academy Research Fellow positions (decisions 250348 and 267514).

Edited by: O. Morgenstern

\section{References}

Ahmad, I., Mielonen, T., Grosvenor, D., Portin, H., Arola, A., Mikkonen, S., Kühn, T., Leskinen, A., Joutsensaari, J., Komppula, M., Lehtinen, K., Laaksonen, A., and Romakkaniemi, S.: Long-term measurements of cloud droplet concentrations and aerosol-cloud interactions in continental boundary layer clouds, Tellus B, 65, 20138, doi:10.3402/tellusb.v65i0.20138, 2013.

Asmi, A., Wiedensohler, A., Laj, P., Fjaeraa, A.-M., Sellegri, K., Birmili, W., Weingartner, E., Baltensperger, U., Zdimal, V., Zikova, N., Putaud, J.-P., Marinoni, A., Tunved, P., Hansson, H.C., Fiebig, M., Kivekäs, N., Lihavainen, H., Asmi, E., Ulevicius, V., Aalto, P. P., Swietlicki, E., Kristensson, A., Mihalopoulos, N., Kalivitis, N., Kalapov, I., Kiss, G., de Leeuw, G., Henzing, B., Harrison, R. M., Beddows, D., O’Dowd, C., Jennings, S. G., Flentje, H., Weinhold, K., Meinhardt, F., Ries, L., and Kulmala, M.: Number size distributions and seasonality of submicron particles in Europe 2008-2009, Atmos. Chem. Phys., 11, 5505-5538, doi:10.5194/acp-11-5505-2011, 2011.

Bauer, S. E., Wright, D. L., Koch, D., Lewis, E. R., McGraw, R., Chang, L.-S., Schwartz, S. E., and Ruedy, R.: MATRIX (Multiconfiguration Aerosol TRacker of mIXing state): an aerosol microphysical module for global atmospheric models, Atmos. Chem. Phys., 8, 6003-6035, doi:10.5194/acp-8-60032008, 2008.

Binkowski, F. S. and Roselle, S. J.: Models-3 Community Multiscale Air Quality (CMAQ) model aerosol component, 1, Model description, J. Geophys. Res., 108, 4183, doi:10.1029/2001JD001409, 2003.

Cotton, W. R. and Anthes, R. A.: Storm and cloud dynamics, International Geophysics Series, Academic Press, San Diego, 883 pp., 1989.

Dentener, F., Kinne, S., Bond, T., Boucher, O., Cofala, J., Generoso, S., Ginoux, P., Gong, S., Hoelzemann, J. J., Ito, A., Marelli, L., Penner, J. E., Putaud, J.-P., Textor, C., Schulz, M., van der Werf, G. R., and Wilson, J.: Emissions of primary aerosol and precursor gases in the years 2000 and 1750 prescribed data-sets for AeroCom, Atmos. Chem. Phys., 6, 4321-4344, doi:10.5194/acp-64321-2006, 2006.
Forster, P., Ramaswamy, V., Artaxo, P., Berntsen, T., Betts, R., Fahey, D. W., Haywood, J., Lean, J., Lowe, D. C., Myhre, G., Nganga, J., Prinn, R., Raga, G., Schulz, M., and Van Dorland, R.: Changes in Atmospheric Constituents and in Radiative Forcing, in: Climate Change 2007: The Physical Science Basis. Contribution of Working Group I to the Fourth Assessment Report of the Intergovernmental Panel on Climate Change, edited by: Solomon, S., Qin, D., Manning, M., Chen, Z., Marquis, M., Averyt, K. B., Tignor, M., and Miller H. L., Cambridge University Press, Cambridge, United Kingdom and New York, NY, US, 2007.

Ghan, S., Laulainen, N., Easter, R., Wagener, R., Nemesure, S., Chapman, E., Zhang, Y., and Leung, R.: Evaluation of aerosol direct radiative forcing in MIRAGE, J. Geophys. Res., 106, 52955316, doi:10.1029/2000JD900502, 2001.

Harrington, D. Y. and Kreidenweis, S. M.: Simulations of sulphate aerosol dynamics-II, Model intercomparison, Atmos. Environ., 32, 1701-1709, 1998.

Hoppel, W. A., Frick, G. M., Fitzgerald, J. W., and Larson, R. E.: Marine boundary layer measurements of new particle formation and the effects nonprecipitating clouds have on aerosol size distribution, J. Geophys. Res., 99, 14443-14459, doi:10.1029/94JD00797, 1994.

Jacobson, M. Z.: Fundamentals of Atmospheric Modeling, Second Edition, Cambridge University Press, New York, 2005.

Kokkola, H., Korhonen, H., Lehtinen, K. E. J., Makkonen, R., Asmi, A., Järvenoja, S., Anttila, T., Partanen, A.-I., Kulmala, M., Järvinen, H., Laaksonen, A., and Kerminen, V.-M.: SALSA - a Sectional Aerosol module for Large Scale Applications, Atmos. Chem. Phys., 8, 2469-2483, doi:10.5194/acp-8-2469-2008, 2008.

Kokkola, H., Hommel, R., Kazil, J., Niemeier, U., Partanen, A.-I., Feichter, J., and Timmreck, C.: Aerosol microphysics modules in the framework of the ECHAM5 climate model - intercomparison under stratospheric conditions, Geosci. Model Dev., 2, 97-112, doi:10.5194/gmd-2-97-2009, 2009.

Liu, X., Easter, R. C., Ghan, S. J., Zaveri, R., Rasch, P., Shi, X., Lamarque, J.-F., Gettelman, A., Morrison, H., Vitt, F., Conley, A., Park, S., Neale, R., Hannay, C., Ekman, A. M. L., Hess, P., Mahowald, N., Collins, W., Iacono, M. J., Bretherton, C. S., Flanner, M. G., and Mitchell, D.: Toward a minimal representation of aerosols in climate models: description and evaluation in the Community Atmosphere Model CAM5, Geosci. Model Dev., 5, 709-739, doi:10.5194/gmd-5-709-2012, 2012.

Mann, G. W., Carslaw, K. S., Spracklen, D. V., Ridley, D. A., Manktelow, P. T., Chipperfield, M. P., Pickering, S. J., and Johnson, C. E.: Description and evaluation of GLOMAP-mode: a modal global aerosol microphysics model for the UKCA composition-climate model, Geosci. Model Dev., 3, 519-551, doi:10.5194/gmd-3-519-2010, 2010.

McComiskey, A., Feingold, G., Frisch, A. S., Turner, D. D., Miller, M. A., Chiu, J. C., Min, Q., and Ogren, J. A.: An assessment of aerosol-cloud interactions in marine stratus clouds based on surface remote sensing, J. Geophys. Res., 114, D09203, doi:10.1029/2008JD011006, 2009.

Mayer, B. and Kylling, A.: Technical note: The libRadtran software package for radiative transfer calculations - description and examples of use, Atmos. Chem. Phys., 5, 1855-1877, doi:10.5194/acp-5-1855-2005, 2005. 
Mohs, J. and Bowman, F.: Eliminating Numerical Artifacts When Presenting Moving Center Sectional Aerosol Size Distributions, Aerosol Air Quality Res., 11, 21-30, doi:10.4209/aaqr.2010.06.0046, 2011.

Nenes, A. and Seinfeld, J. H.: Parameterization of cloud droplet formation in global climate models, J. Geophys. Res., 108, 4415, doi:10.1029/2002JD002911, 2003.

Pringle, K. J., Tost, H., Message, S., Steil, B., Giannadaki, D., Nenes, A., Fountoukis, C., Stier, P., Vignati, E., and Lelieveld, J.: Description and evaluation of GMXe: a new aerosol submodel for global simulations (v1), Geosci. Model Dev., 3, 391-412, doi:10.5194/gmd-3-391-2010, 2010.

Salil, M., Evans, K. J. Truesdale, J. E., Hack, J. J., and Lamarque, J.-F.: Interannual Tropospheric Aerosol Variability in the Late Twentieth Century and Its Impact on Tropical Atlantic and West African Climate by Direct and Semidirect Effects, J. Climate, 25, 8031-8056, doi:10.1175/JCLI-D-12-00029.1, 2012.

Seigneur, C., Hudischewskyj, A. B., Seinfeld, J. H., Whitby, K. T., Whitby E. R., Brock J. R., ann Barnes, H. M.: Simulation of Aerosol Dynamics: A Comparative Review of Mathematical Models, Aerosol Sci. Technol., 5, 205-222, 1986.

Seinfeld, J. H. and Pandis, S. N.: Atmospheric Chemistry and Physics: From Air Pollution to Climate Change, 2nd Edn., J. Wiley, New York, 2006.

Sihto, S.-L., Kulmala, M., Kerminen, V.-M., Dal Maso, M., Petäjä, T., Riipinen, I., Korhonen, H., Arnold, F., Janson, R., Boy, M., Laaksonen, A., and Lehtinen, K. E. J.: Atmospheric sulphuric acid and aerosol formation: implications from atmospheric measurements for nucleation and early growth mechanisms, Atmos. Chem. Phys., 6, 4079-4091, doi:10.5194/acp-6-4079-2006, 2006.
Stier, P., Feichter, J., Kinne, S., Kloster, S., Vignati, E., Wilson, J., Ganzeveld, L., Tegen, I., Werner, M., Balkanski, Y., Schulz, M., Boucher, O., Minikin, A., and Petzold, A.: The aerosol-climate model ECHAM5-HAM, Atmos. Chem. Phys., 5, 1125-1156, doi:10.5194/acp-5-1125-2005, 2005.

Vignati, E., Wilson, J., and Stier, P.: M7: An efficient size-resolved aerosol microphysics module for large-scale aerosol transport models, J. Geophys. Res., 109, D22202, doi:10.1029/2003JD004485, 2004.

Vignati, E., Karl, M., Krol, M., Wilson, J., Stier, P., and Cavalli, F.: Sources of uncertainties in modelling black carbon at the global scale, Atmos. Chem. Phys., 10, 2595-2611, doi:10.5194/acp-102595-2010, 2010.

Whitby, E. R. and McMurry, P. H.: Modal Aerosol Dynamics Modeling, Aerosol Sci. Technol., 27, 673-688, 1997.

Zhang, Y., Seigneur, C., Seinfeld, J. H., Jacobson, M. Z., and Binkowski, F. S.: Simulation of aerosol dynamics: A comparative review of algorithms used in air quality models, Aerosol Sci. Technol., 31, 487-514, 1999.

Zhang, Y., Easter, R. C., Ghan, S. J., and Abdul-Razzak, H.: Impact of aerosol size representation on modeling aerosol-cloud interactions, J. Geophys. Res., 107, 4558, doi:10.1029/2001JD001549, 2002.

Zhang, K., O’Donnell, D., Kazil, J., Stier, P., Kinne, S., Lohmann, U., Ferrachat, S., Croft, B., Quaas, J., Wan, H., Rast, S., and Feichter, J.: The global aerosol-climate model ECHAM-HAM, version 2: sensitivity to improvements in process representations, Atmos. Chem. Phys., 12, 8911-8949, doi:10.5194/acp-12-89112012, 2012. 